\title{
SOCIOLOGIA PÚBLICA: engajamento e crítica social em debate
}

INTRODUÇÃO

\author{
Ruy Braga* \\ Marco Aurélio Santana ${ }^{* *}$
}

Em agosto de 2004, Michael Burawoy, conhecido sociólogo e etnógrafo marxista do trabalho, foi eleito presidente da Associação Sociológica Americana (ASA). Como ocorre rotineiramente com os presidentes recém-eleitos, ele contava com um ano para preparar sua conferência presidencial, pois, nessa associação, a eleição dista em doze meses da posse nas funções. Tendo já desenvolvido uma reflexão a respeito da sociologia contemporânea - sobre os diversos tipos contemporâneos de sociologia e de sociólogos, trabalhando dentro e fora das universidades-, ele decidiu consagrar sua conferência a esse tema: a "sociologia pública".

O resultado de um ano de debate com diferentes públicos foi um estudo aprofundado acerca das múltiplas práticas sociológicas contemporâneas - pensadas, naturalmente, a partir do exemplo estadunidense -, mas buscando sempre dialogar

* Doutor em Ciências Sociais. Professor do Programa de PósGraduação em Sociologia da Universidade de São Paulo.

Av. Prof. Luciano Gualberto, 315 - sala 1063 - Cidade Universitária. Cep: 05508-010. São Paulo - Brasil. ruy.braga@uol.com.br

* * Doutor em Sociologia. Professor do Programa de PósGraduação em Sociologia e Antropologia da Universidade Federal do Rio de Janeiro.

Largo de S. Francisco, 1 - Sala 420. Centro. Cep: 20051 070 - Rio de Janeiro-RJ. msantana@ifcs.ufrj.br com as demais realidades nacionais. ${ }^{1}$ De acordo com Burawoy, a sociologia encontrar-se-ia contemporaneamente melhor preparada para retraduzir, de maneira sistemática, seu próprio saber disciplinar, no sentido de devolver o conhecimento científico a suas fontes inspiradoras, tornando públicas as questões referentes a problemas privados, “... regenerando a fibra moral da sociologia".

O diagnóstico elaborado por Burawoy parte de uma constatação muito próxima daquela presente também em Bourdieu, ou seja, a de que o aumento de interesse por uma sociologia pública deriva, em parte, da reação ao "avanço generalizado da privatização”. Por sociologia pública, Burawoy (2005) compreende genericamente um "estilo" de se fazer sociologia "engajada" e que não confunde a indispensável busca da objetividade científica - com todas as exigências éticas e compromissos valorativos inerentes a essa busca - com a adoção ostensiva de uma neutralidade moral ou mesmo política.

Ao contrário, trata-se de um estilo de se fazer sociologia que procura iluminar os elos exis-

${ }^{1}$ Seguindo a tradição da Associação Sociológica Americana, o texto da conferência presidencial foi publicado na American Sociological Review (2005). 
tentes entre os problemas privados e os desafios públicos a partir da centralidade axiológica dos conhecimentos dos subalternos. Trata-se, antes de tudo, de um "estilo", na medida em que supõe uma maneira de escrever e de se comunicar com diferentes públicos, além de supor, também, uma modalidade determinada de engajamento intelectual. Em seu discurso presidencial, Burawoy ofereceu alguns indícios dessa suposta elevação do interesse pela sociologia pública.

Segundo ele, a sociologia política dos Estados Unidos, por exemplo, teria passado, nas últimas duas décadas, do estudo das virtudes da democracia representativa para o estudo das relações do Estado com as classes sociais (enfatizando a necessidade do aprofundamento da participação democrática). Além disso, a sociologia do trabalho teria transitado definitivamente da análise dos processos de adaptação ao estudo da dominação sobre os trabalhadores. Finalmente, mesmo a teoria sociológica teria privilegiado uma visão "radical" de Weber e Durkheim, somada à revalorização do pensamento do próprio Marx.

Burawoy advoga que, contra a privatização e a degradação do mundo social, a sociologia pública deveria se transformar em um meio de revitalização da própria ideia de "público", tão vilipendiada pela tempestade provocada pela ofensiva neoliberal (2005, p. 7). Além da premissa "conjuntural" invocada em favor da radicalização política do saber disciplinar sociológico, Burawoy acrescentou uma problematização a respeito da natureza dos "compromissos axiológicos" inerentes aos diferentes tipos de sociologia pública: a "tradicional" e a "orgânica".

Com a sociologia pública tradicional, os grupos de pessoas visadas normalmente são "invisíveis", na medida em que não produzem muita interação interna, além de "passivos", por não constituírem um movimento ou organização. "Existe, contudo, outro tipo de sociologia pública - a sociologia pública orgânica - na qual o sociólogo trabalha em estreita conexão com um público visível, denso, ativo, local e, via de regra, na contracorrente" (2005, p. 7). A sociologia pública "orgânica" suporia um processo de mútua educação entre o sociólogo e o público.

A sociologia pública orgânica se constitui na relação dialógica entre o sociólogo e o público, na qual cada parte apresenta sua agenda e trata de ajustá-la à agenda do outro. Na base desse estilo de se fazer sociologia, vamos encontrar, naturalmente, um interesse de caráter "reflexivo" de que esse diálogo seja ampliado no interior da comunidade acadêmica e aborde os fundamentos de seus programas de pesquisas.

Afinal, "sociologia para quem?" e "sociologia para quê?" Parece-nos que essas questões bourdieusianas são realmente significativas para qualquer modalidade de sociologia reflexiva, seja ela "crítica" ou "pública". Em concordância - e de forma complementar - com essa preocupação reflexiva de fundo, a sociologia pública orgânica se interessa pela imagem pública da sociologia, o que supõe a apresentação dos resultados científicos de forma acessível, o cuidado com o ensino básico da sociologia e a redação de material didático. Dessa forma, a sociologia pública orgânica busca garantir um diálogo entre os sociólogos e seus públicos, capaz de superar a usual falta de conexão entre o habitus sociológico ${ }^{2}$ e a estrutura global do campo disciplinar, responsáveis, em grande medida, pelos excessos "compartimentalizantes" a que frequentemente submetem o saber disciplinar.

É bem verdade que existe o risco "ideológico", isto é, o risco de o saber disciplinar ser instrumentalizado por forças políticas exteriores ao campo e cujos interesses predominantes se apresentem como refratários ao ethos científico e ao compromisso com os resultados das diferentes pesquisas. ${ }^{3}$ Contudo, o reconhecimento da existência desse tipo de risco não deve servir de desculpa para obliterar a questão fundamental

\footnotetext{
Um instigante exemplo apresentado por Burawoy a propósito da conexão entre o habitus sociológico e a estrutura do campo é o do sociólogo negro, professor da Universidade de Atlanta e ativista dos direitos civis - autor de Black reconstruction (1934), entre outros clássicos da sociologia estadunidense - W. E. B Du Bois: "Suas [de Du Bois] incessantes campanhas em favor da justiça racial foram o topo da sociologia pública, ainda que, naturalmente, seu objetivo último fosse sempre a transformação da política." (2005, p. 14).

$\mathrm{Na}$ realidade, as disciplinas são campos de poder nos quais a interdependência recíproca frequentemente con-
} 
endereçada ao próprio campo disciplinar pela sociologia pública: é realmente viável - ou sustentável, para não dizer desejável - uma sociologia científica livre de qualquer compromisso público?

Essa questão, na verdade, remete a outra, também proposta por Burawoy: afinal, o que poderia ser a sociologia se não um compromisso com diversos públicos sobre diferentes questões públicas? Implícito nessa segunda questão está o problema que diferencia, em última instância, a sociologia pública tradicional da sociologia pública orgânica: a centralidade axiológica - e, consequentemente, a capacidade explicativa - dos conhecimentos dos subalternos. Conforme o registro dessa centralidade é que podemos compreender integralmente a interpretação de Burawoy segundo a qual o etnossociólogo é - ou deve ser - uma espécie de intelectual orgânico da humanidade cuja tarefa mais importante consiste em lutar contra a fetichização da existência humana.

Para tanto, a sociologia pública procura fazer visível o invisível, tornar público o privado. Em suma: desfetichizar as relações sociais seguindo a trilha aberta por Gramsci (1999), quando definiu a função primacial do intelectual orgânico: "elaborar e tornar coerentes os problemas colocados pelas massas". Da mesma forma, o desenvolvimento do conhecimento público frequentemente se produz por meio de uma "colaboração multidisciplinar", como, por exemplo, o caso da "investigação participativa”, que coloca em comunicação as comunidades acadêmicas de disciplinas complementares.

A sociologia pública orgânica supõe esse tipo de vínculo com os diferentes públicos criados, associados, suportados ou estimulados por ela: um liame essencialmente solidário estabelecido sobre o terreno da centralidade axiológica do conhecimento dos subalternos: "Uma comunidade define uma questão - moradia, poluição ambiental, doenças, salário mínimo, escolarização... - e então trabalha

verte-se em relação assimétrica e antagônica. Em consequência, o "risco" - menos alardeado, mas muitíssimo mais presente - que o campo disciplinar corre é o da dominação do conhecimento instrumental sobre o conhecimento reflexivo. conjuntamente com uma equipe multidisciplinar para enquadrar e estabelecer as aproximações às questões" (Burawoy, 2005, p. 24). Como é possível perceber, estamos no terreno do sociólogo como um "companheiro", conforme a expressão empregada por Alvin Goldner (1968) em seu conhecido ensaio.

Se por sociedade civil entendermos, a exemplo de Burawoy, um campo de lutas onde as forças sociais do trabalho - partidos políticos operários ou radicais, sindicatos de trabalhadores, instituições educacionais, organizações ecologistas e feministas, comunidades religiosas, imprensa popular e uma ampla variedade de organizações de voluntários - enfrentam e resistem às investidas das forças sociais do capital, concluiremos que a sociologia pública busca estudar o Estado e a economia do ponto de vista das classes "oprimidas e combatentes". Em resumo, o ponto de vista da sociologia é o ponto de vista do conflito: "Nos tempos da tirania do mercado e do despotismo de Estado, a sociologia -e, particularmente, sua faceta pública - defende o interesse da humanidade" (Burawoy, 2005, p. 24).

Como já aludido, entendemos que a virtuosidade da sociologia pública localiza-se em sua sensibilidade política e axiológica. Ou seja, na "conexão" da sociologia com a sociedade civil. Parte do diagnóstico que inspira o apelo por uma sociologia pública orgânica radica exatamente na ideia de que, durante os últimos trinta anos, os interesses das classes subalternas foram sendo progressivamente aviltados pelo neoliberalismo. Ainda hoje, a oposição a essas forças tem sua origem na sociedade civil, tanto local quanto nacional e internacional.

Contudo, vale a pergunta: é possível tornar coincidentes os pontos de vista da sociologia e das classes oprimidas e combatentes? Quer por seu radicalismo crítico, quer por sua posição institucional (afinal, tratava-se da antiga presidência da ASA), tal proposta produziu naturalmente um vivo debate na comunidade sociológica estadunidense. Do lado das críticas a Burawoy, é possível dizer que muitos consideraram a proximidade da sociologia pública com o marxismo uma fonte de problemas, na medida em que serviria para enraizar ainda mais 
as divisões existentes no interior do campo disciplinar. Por outro lado, muitos reprovaram a sociologia pública argumentando que a sociedade civil não é a única arena, e a justiça social não é a única ferramenta para “defender a humanidade” (Boyns; Fletcher, 2005; Turner, 2005; Brint, 2005). ${ }^{4}$

Outros, ainda, verificaram problemas e ambiguidades relacionados à operacionalização da proposta no que concerne às pesquisas sociológicas (McLaughlin, Kowalchuk e Turcotte, 2005). Ulrich Beck (2005), por exemplo, considerou simplesmente que o mainstream sociológico não se encontra realmente preparado para esse tipo de "aventura” militante e que, antes de garantir uma voz pública para a sociologia, devemos reinventá-la para o século XXI. No entanto, a mais áspera das críticas recebidas por Burawoy foi desferida por Mathieu Deflem (2005), que considera que a sociologia pública não é "nem sociologia, nem pública”: ela seria, para Deflem, epistemologicamente inconsistente, estaria confinada a determinadas áreas de pesquisa, seria, portanto, sectária, além de utópica... Em suma, seria uma espécie de ideologia marxista disfarçada de ciência social. ${ }^{5}$

O dossiê que o leitor tem em mãos pretende apresentar, de uma maneira plural, essa proposta para o público brasileiro e, ao mesmo tempo, colaborar com o desenvolvimento do debate acerca da

Evidentemente, revalorizar as forças sociais presentes na sociedade civil não implica fetichizar os interesses subalternos. Na realidade, também o campo da sociedade civil encontra-se fraturado por segregações, dominações e explorações de várias ordens. Contudo, concordamos com Burawoy quando afirma que, "na conjuntura atual, [a sociedade civil] ainda é o melhor terreno possível para a defesa da humanidade”. Não o "único”, mas o "melhor". Assim, a questão estratégica a ser respondida pela sociologia diante do processo de privatização do mundo social é exatamente esta: seremos capazes de assumir um compromisso - inspirado por um século de extensa investigação, de elaboração teórica, de investigações práticas e de pensamento crítico - com os movimentos sociais que vá além dos limites acadêmicos tradicionais?

${ }^{5}$ Uma parte substantiva das críticas à sociologia pública deriva, como é possível notar, da sua relação com o marxismo. Sejamos claros: Burawoy é um reconhecido sociólogo marxista. Contudo, sua proposta, a nosso ver, não consiste em diluir a cientificidade sociológica no marxismo, ou vice-versa. Trata-se, na realidade, antes de mais nada, de definir um espaço para um saber crítico e reflexivo, engajado com públicos extra-acadêmicos e capaz de tornar públicas questões sociais relevantes. Não existe um vínculo necessário da sociologia pública com o marxismo - apesar de ele, evidentemente, reconhecerse, em certa medida, naquela. sociologia pública entre nós.

Abrindo o dossiê, o artigo de Michael Burawoy, baseado no discurso por ele dirigido à Sociedade Japonesa de Sociologia, na Universidade de Tohoku, recoloca as formulações centrais do que seria a sociologia pública a partir do cenário aberto com a profunda crise por que passa o sistema capitalista. Mesmo ciente das diferentes tradições nacionais e da desigualdade internacional, e apesar delas, Burawoy acredita que, como sociólogos, compartilharíamos "uma ambição e uma missão comum”, que seria o combate ao paradigma baseado no fundamentalismo do mercado, que atualmente demonstraria "gravíssimos sinais de crise e de exaustão”.

Ao mesmo tempo em que considera a eleição de Barack Obama um “evento histórico”, avalia o contexto de piora da crise em que ela se dá, assinalando uma possível mudança na posição americana contra o fundamentalismo de mercado. Contudo, chama atenção para o fato de que a démarche dessa mudança é um tanto contraditória e não se pode dizer ainda a “coloração ideológica” que assumirá e seu alcance, bem como "sua conexão com os movimentos sociais subalternos e se suas respostas permanecerão confinadas ao âmbito nacional ou se elas também deverão ser globais”.

De todo modo, partindo da proposta da sociologia pública, Burawoy afirma que, independentemente das direções assumidas pelo governo Obama, os sociólogos deveriam "canalizar as reações em direção à criação de uma sociedade civil mais fortalecida e democrática; e de uma esfera pública mais robusta e inclusiva”. Isso seria fundamental não só porque se trataria de uma proposta “mais progressista”, mas, sobretudo, porque a sociologia retira sua vitalidade exatamente da sociedade civil. Assim, segundo Burawoy, "nestes tempos de indefinição e de insegurança”, a sociologia pública, tem "tanto a oportunidade como a obrigação de defender os fundamentos que sustentam a sociologia e, por consequência, o interesse comum e universal”.

Mas, para tanto, os sociólogos precisam sair das "conchas dentro das quais se abrigaram en- 
quanto a euforia do mercado rugia ao seu redor". Faz parte de sua tarefa de sociólogos "lutar por um contra-ataque centrado na sociedade civil, e não por uma reação que instale um governo despótico ou apele para uma reforma utópica do mercado".

O segundo artigo, escrito por Alain Touraine, parte da aceitação das principais orientações de Burawoy quanto à sociologia pública e a sua relação com outros estilos do fazer sociológico, principalmente no que diz respeito ao posicionamento de que "é chegado o momento de superarmos a contradição insustentável entre a sociologia profissional e a sociologia crítica", as quais, isoladamente são "igualmente irrelevantes para nossas expectativas".

Mas essa aceitação se dá a partir do que ele chama "de uma perspectiva privilegiada”. Isto é, como "um forasteiro que elabora seus próprios conceitos, ao aproveitar elementos provenientes da vida intelectual europeia, estadunidense e latinoamericana”. Por tal via, formula um programa distinto, à medida que, ao invés "de considerar a relação de oposição ou o relacionamento de complementaridade entre a sociologia pública e a sociologia profissional, como diferentes modalidades de conhecimento", ele tem como proposição o foco "nas diferenças teóricas que existem entre as principais orientações da pesquisa sociológica, mas considerando que tais ideias são afetadas por diferenças nas situações históricas e culturais sob as quais vivemos".

O ponto de partida de Touraine é o de que a sociologia clássica está em declínio. Ela tem se "apresentado como sociologia profissional, mas sem o direito de fazê-lo, pois a relevância conferida ao critério profissional precisaria ser dada a todas as outras orientações da sociologia”. A sociologia pública ocuparia o lugar central exatamente porque "ela é a busca por atores". Sua centralidade residiria em nossa desconfiança em relação aos "filósofos da história ou doutrinas políticas" e em nossa "necessidade de identificar os principais "problemas sociais do nosso tempo".

No caso dos dois outros "tipos de orientação”, a "sociologia para políticas públicas e a socio- logia crítica são duas orientações que se completam", podendo ser também consideradas como "subprodutos da sociologia pública". Finalmente, teríamos uma nova sociologia profissional que "aparece como o estudo de instituições que não estão mais dedicadas às necessidades dos sistemas sociais, mas sim à proteção dos indivíduos e grupos contra as forças sociais dominantes".

Em seu entendimento, a sociologia pública não pode se reduzir "à simples difusão das pesquisas profissionais". Na medida em que nos dirigimos "a qualquer espécie de público", isso significaria, antes de tudo, "falar sobre 'direitos' de uma forma que corresponda às capacidades e expectativas destes públicos". Mas, por outro lado, isso não significaria dizer que deveríamos "formular uma ideologia que seja congênita aos interesses e valores dos públicos".

Na verdade, sendo a sociologia o estudo do "comportamento normativamente orientado", o que ela faria seria explicitar "a presença, numa dada situação e para determinada categoria de indivíduos, de uma disputa em torno de direitos". O grau de autonomia dos atores sociais, "em face das estruturas políticas" e "em face de sua nova atribuição defensiva”, definiria aquela que seria “a importância relativa de cada uma das quatro orientações da sociologia”. Esse nível de autonomia dos atores sociais variará dependendo das diferentes situações históricas e geográficas. Nesse sentido, "nós não podemos fechar as fronteiras" entre elas que nos fornecerão exemplos da variação para mais ou para menos nessa autonomia.

Touraine traça as linhas de desenvolvimento distinto seguidas pelos "quatro tipos principais de orientação" da sociologia, quando pensamos em sua trajetória nos EUA, na Europa ou na América Latina. Nesse sentido, concordando com Burawoy, Touraine assinala que “... a diferenciação interna da sociologia precisa ser combinada com sua integração ou, pelo menos, com a influência recíproca de suas principais orientações". Seria a combinação entre a sociologia pública e a sociologia profissional, das pesquisas empíricas com análises mais teóricas, que nos possibilitaria não só a 
identificação dos "principais 'problemas sociais' do nosso tempo", mas, sobretudo, explicitar "as condições de programas de reforma política e moralmente eficazes".

No terceiro artigo do dossiê, Jonathan Turner assume posição franca e abertamente crítica à proposta de Burawoy por uma sociologia pública. Segundo ele, “...existem perigos reais em perseguir agressivamente a presença pública da sociologia”. Isso porque, tomando a distinção de Burawoy entre as quatro sociologias, Turner não acha que elas possam "ser facilmente harmonizadas". Para ele, "a sociologia pública [...] não soluciona os pontos de fratura da disciplina; somente os ressalta". Além do mais, privilegiaria "duas das quatro sociologias, rejeitando as outras duas: a ciência e a prática”. Nesse sentido, na perspectiva de Turner, seríamos "conduzidos por Burawoy na direção errada". Por seu turno, Turner recomenda "justamente a direção oposta, privilegiando a ciência e a prática como uma melhor direção para a sociologia, agora e no futuro". De outra maneira, como com Burawoy, apenas faríamos a sociologia perder relevância.

Em sua visão, “... se os sociólogos expõem suas políticas aos públicos, em muitas sociedades eles possivelmente prestarão ainda menos atenção aos sociólogos do que atualmente o fazem". Nesses termos, Turner defende a ideia de que para "que a sociologia exerça influência duradoura nas políticas públicas e nas decisões tomadas pelos que detêm o poder, precisamos engajar públicos como cientistas, com explicações que sejam úteis". Já a proposta da sociologia pública, que, para Turner, nada mais seria do que "engajar plateias como 'cruzadas morais", tenderia "a reduzir ainda mais a influência já bastante limitada que os sociólogos exercem em debates e decisões importantes".

Em seu entendimento, a “... sociologia pública significa que os sociólogos devem tomar parte dos movimentos sociais - na realidade, a 'vanguarda' desses públicos, a partir da segurança dos nossos gabinetes na academia”. Contraditando tal proposta, ele avalia que não "é preciso que os sociólogos digam às pessoas que elas têm problemas; elas já o sabem”. Elas “não precisam dos sociólogos de vanguarda para engajá-las em torno de um movimento de organização. Elas, geralmente, já têm habilidade para tanto". O que esses públicos precisariam é do "conhecimento - imparcial e preciso sobre o mundo social que pode ser utilizado pelos públicos, clientes, formuladores de políticas ou quem tiver um problema de organização social".

Mas Turner diagnostica o que seria a existência de "uma grande lacuna entre a teoria e a pesquisa", sendo "difícil para a sociologia ter muito que dizer em relação a questões importantes". A solução desse problema viria quando os "seus teóricos desenvolvam teorias e seus pesquisadores as testem, de modo que a disciplina consiga acumular mais conhecimento. Sem conhecimento, o que vamos dizer aos nossos 'públicos'?"

Apesar de se dizer solidário "com uma sociologia levada a sério", Turner se diz não "convencido de que uma sociologia, carregada ideologicamente, consiga fortalecer-nos e, mais importante, conceder-nos um lugar à mesa do poder, onde estão sendo tomadas as decisões mais importantes que afetam o bem estar das pessoas". Para Turner, ele ficaria mais esperançoso, "se a ciência conseguisse realmente disciplinar esse discurso". Mas ele vê "poucas possibilidades de a sociologia pública ser disciplinada" pela ciência.

Turner assinala que o "melhor caminho para que os sociólogos atraiam os públicos e os formuladores de políticas é como engenheiros, embora usando um outro rótulo". Isso significaria dizer que "começamos a criar princípios gerais, reduzidos à expressão mais simples em métodos empíricos, para os problemas dos clientes". Assim, a ideia seria "tornar a prática sociológica mais eficiente rumo a uma mentalidade mais de engenharia". Para tanto, "a sociologia precisa treinar novamente seus praticantes para que sejam mais teóricos; e os teóricos precisam afirmar as teorias de maneira formal, para que fique claro o que a teoria postula". Nesse sentido, os "teóricos precisam começar a montar o corpus de conhecimento sobre os processos sociais de modo que possam ser usados pelos praticantes" da sociologia. 
Abrindo a participação brasileira desse dossiê, Simon Schwartzman problematiza a visão de Burawoy a respeito do vínculo orgânico da sociologia pública com os movimentos sociais, alegando que a liberdade de reflexão e o rigor das pesquisas científicas que a academia é capaz de garantir são os verdadeiros pilares da ação dos sociólogos nos vários campos de intervenção da sociologia. Assim, o espaço privilegiado da ação sociológica crítica e reflexiva não seria tanto a arena pública tradicional ou orgânica, mas o universo acadêmico: "Diferente de Burawoy, acredito que é no mundo acadêmico, da liberdade de pesquisa e do rigor científico, que deveria estar a âncora que desse ao sociólogo a liberdade de trabalhar com autonomia e independência intelectual nos outros setores".

No intuito de aprofundar o debate acerca dos modos de trabalho e do objeto da sociologia, Schwartzman apresenta um quadro geral do processo de institucionalização da sociologia brasileira, destacando o papel desempenhado por algumas entidades profissionais, especialmente o Sindicato dos Sociólogos do Estado de São Paulo (Sinsesp). Ao descrever em traços gerais o atual estado dos programas de pós-graduação em sociologia no país e reconhecer o potencial contido na recém-conquistada obrigatoriedade do ensino de sociologia nas escolas secundárias, Schwartzman aponta na realidade para a ampliação da importância da sociologia brasileira no debate público. Contudo, isso carregaria também consigo o risco da subordinação da disciplina aos interesses das organizações não-governamentais da sociedade civil e do trabalho na administração pública, setores privilegiados da ação dos sociólogos brasileiros, conforme o autor.

É nesse sentido que o principal desafio percebido por Schwartzman para os sociólogos do país seria esse: “(...) estar atento e sintonizado com esta agenda pública e, ao mesmo tempo, consolidar uma sociologia que mantenha sua independência e sua relevância, tanto em relação aos rituais acadêmicos quanto em relação às organizações e movimentos sociais com os quais dialoga ou dos quais participa". Assim, o futuro da sociologia brasileira não estaria localizado tanto na relação dos sociólogos com os movimentos sociais, mas sim na relação desses com uma pauta pública de intervenções estruturadas por meio da autonomia do campo acadêmico.

Em seu artigo, Leonardo Mello e Silva assinala a importância atribuída ao ator pela sociologia pública, partindo daí para explorar suas implicações “... para a pesquisa ordinária em sociologia”, sempre as voltas com o dilema entre agência e estrutura, só para ficar em uma das polaridades das muitas que se desenvolveram ao redor do mesmo tipo de debate. Nesse sentido, recuperando esse dilema por meio da sociologia pública, o autor trabalha a "dimensão moral da disciplina, assim como alguns paradoxos que ela acaba acarretando".

Mello e Silva percebe a sociologia da ação desenvolvida por Alain Touraine como "o principal contraponto" da sociologia pública. Dessa forma, ele indica a existência de "muitos pontos em comum entre as duas abordagens". Contudo, não deixa de perceber também pontos divergentes. Esses seriam relacionados "mais à concepção da sociologia diante dos problemas do civismo e da política, de maneira ampla" e menos aos procedimentos metodológicos. O autor visa a articular a discussão sobre as "vicissitudes de uma sociologia da ação" (e suas implicações públicas) com "o civismo e a política".

Apesar da indicação de que as formas de intervenção propostas pela sociologia da ação de Touraine "ecoam as divisões do fazer sociológico presentes no esquema de Burawoy", Mello e Silva chama nossa atenção para os dois momentos históricos distintos das duas formulações. Touraine escreveria em um período de ascensão dos movimentos sociais nos países do centro e da periferia, em que se apostava neles "como contratendência ao controle social e à socialização normalizadora oriunda de agências repressivas, formativas ou integradoras (Estado ou Empresa)". Já Burawoy, formula sua teoria em um período distanciado trinta anos no tempo. "Não é o contexto do Welfare State, nem muito menos das 'energias utópicas', mas, ao contrário, do neoliberalismo e da fragmentação de 'públicos' esgarçados, ao invés de um es- 
paço público ou de uma sociedade civil que aponta para o Estado ou a política”.

Assim, Mello e Silva assinala que “... a intervenção sociológica foi concebida para o estudo dos movimentos sociais, e esses também têm uma história e um contexto: a partir do final dos anos 1960, na Europa; a partir do final dos anos 1970, no Brasil. Hoje, o cenário é bem diferente de quando os movimentos sociais emergiram". Isso tornaria "difícil conceber como movimentos sociais possam emergir desse terreno menos e menos coletivo". Por outro lado, como ele mesmo percebe "longe está uma pacificação dos conflitos e uma ausência de sofrimento e de experiência de exploração e opressão, produzidas socialmente".

Em um quadro como esse, a "intervenção sociológica, pensada para atuar junto aos elementos mais salientes dos movimentos sociais, fica, no âmbito do mundo do trabalho e do protesto coletivo, desarmada. Ela é pertinente para as ocasiões de 'ascenso' (para usar uma linguagem militante), mas não é tão boa para as ocasiões de 'descenso', como se observa na atualidade”. A tarefa do sociólogo informado pelas orientações da intervenção aprofundar-se-ia, já que ele "precisaria ir mais fundo e adotar uma postura decididamente empática”, além de "partilhar do drama social dos atores com os quais está envolvido pelo desejo de produzir algum conhecimento relevante: essa seria a condição para o entendimento completo da situação [...] como conflito social. Esse é um dos limites, hoje, da aplicação do paradigma da intervenção sociológica. Mas não significa que as promessas que ela levantou estejam ultrapassadas ou impertinentes. A sociologia pública acaba revolvendo, indiretamente, essas mesmas questões".

As duas, inclusive, enfrentariam "perigos análogos", já apontados pelos dois autores: "o vanguardismo, por um lado, e, por outro lado, a imersão completa no grupo, quando os pesquisadores são capturados pela comunidade". Segundo Melo e Silva, isso comporia "uma atualização de velhos dilemas que sempre vêm à tona quando se trata de escapar do normativismo de uma postura pretensamente objetiva e exterior, nas ciências sociais".
O artigo de Marco Aurélio Santana e Ruy Braga, analisando "a relação estabelecida entre a sociologia do trabalho e o sindicalismo no Brasil", a partir de três momentos diferentes, e tendo como pano de fundo as sucessivas conjunturas políticas e econômicas, parte de hipótese de que "a sociologia do trabalho no Brasil foi marcada, em seus primórdios, pela busca de afirmação e profissionalização"; "posteriormente, desenvolveu um forte engajamento político-social, assumindo um caráter público e servindo para conformar certas identidades sociais"; e, "por fim, teria derivado para uma sociologia para as políticas públicas".

Para os autores, no "decorrer do período de profissionalização das ciências sociais no Brasil, [...] as visões totalizantes de nossa realidade social foram, até certo ponto, secundarizadas pelos estudos que priorizavam trabalhos mais voltados para o esclarecimento sistemático de aspectos até então não suficientemente estudados de nossa formação histórica". Eles acompanhariam pari passu "a profissionalização das ciências sociais no Brasil", adquirindo formas "claramente identificadas com as diferentes interpretações da sociedade capitalista industrial moderna". Tratava-se mesmo "de uma luta simbólica, travada no terreno científico, contra as ideologias político-programáticas orientadas por tradições partidárias. Daí o desejo de forte diferenciação verificado em alguns dos mais importantes estudos dessa época".

Já na conjuntura seguinte, "os sociólogos brasileiros mostraram-se profundamente atraídos pelo caráter inovador das demandas surgidas no contexto das grandes lutas do final dos anos 1970". Em um "momento marcado pelo avanço dos movimentos populares contra o regime autoritário, ajudaram a construir a identidade desse novo sujeito político: o 'novo sindicalismo". Certo "vínculo 'orgânico' entre estudiosos e sindicalistas foi sendo forjado, legitimando a opinião segundo a qual esse sindicalismo representou uma reação de um grupo social" importante.

Nesses termos, seria "possível afirmar que, ao longo das décadas de 1970 e 1980, forjou-se uma sociologia pública 'orgânica' do trabalho no 
Brasil”, conforme a definição de Burawoy.

Com as mudanças trazidas pelos anos 1990, "a direção muda no sentido de uma audiência cada vez mais extra-acadêmica cujos interesses gravitam em torno das políticas públicas e, consequentemente, do poder de Estado". Na visão dos autores, a "vitória eleitoral de Luiz Inácio Lula da Silva, em 2002, parece ter coroado esse novo ciclo de profissionalização, com a entrega do Ministério do Trabalho e Emprego (MTE) para o controle da Central Única dos Trabalhadores (CUT)”. Assim, seria "digna de nota a incorporação direta de acadêmicos aos órgãos do governo [...] os quais passaram à formulação imediata, ao debate e à implementação de políticas públicas”. Isso imporia a questão de se a "sociologia pública terá sido definitivamente substituída por uma sociologia para as políticas públicas no Brasil? Ou estaria o pêndulo dos estilos sociológicos prestes a oscilar novamente, inaugurando um novo período?".

Fechando o dossiê, temos o artigo de Elísio Estanque. Nele, o autor parte da apresentação da experiência do Centro de Estudos de Sociologia (CES), da Universidade de Coimbra. Esse centro tem como orientação "construir um conhecimento progressista, transformador e emancipatório, destinado a reforçar o espaço público". Pretende "usá-lo como auxiliar para ver para além do manto de opacidade que as instituições e o poder hegemônico tendem a lançar sobre a realidade, ou, pelo menos, aquela parte da realidade social tendente a pôr em causa as leituras dominantes e a incomodar a ordem estabelecida". Em outras palavras, recusar-se-ia "a limitar-se a justificar o que existe só porque existe, e estar atento às ausências e às emergências".

Estanque fornece "uma amostra dos temas de estudos que temos desenvolvido, guiados por essa orientação, ou seja, procurando usar a reflexão e a análise sociológica para, a partir dela [...], intervir na esfera pública, procurando dirigir o nosso conhecimento não apenas para as instituições ("policy making”), não apenas para a comunidade acadêmica (numa perspectiva "profissional” ou “crítica”), mas para os públicos subalternos e plurais, no sentido de disseminar informa- ção e conhecimento inovador capaz de instigar a participação e a cidadania ativa".

A preocupação do autor seria "a de divulgar, junto à comunidade brasileira dos cientistas sociais, algumas das leituras e diagnósticos que temos proposto sobre as tendências de mudança no período recente, no campo das relações de trabalho e do sindicalismo". Na visão de Estanque, a "reflexão sobre a questão laboral e social de uma maneira geral não poderia, evidentemente, deixar de ser observada sem se levar em conta alguns dos traços específicos da sociedade portuguesa, mostrando as suas vulnerabilidades particulares, que remetem para a história recente do país e para as dificuldades que vem enfrentando na aproximação aos padrões europeus".

No entendimento do autor, qualquer "diagnóstico que se faça acerca da questão laboral - seja ele com respeito ao caso português, brasileiro ou outro -, na difícil conjuntura internacional que hoje vivemos, não pode circunscrever-se à realidade presente [...], devendo, antes, perspectivá-la no quadro de um processo histórico mais amplo e de um quadro estrutural mais vasto e profundo". Nesses termos, o "campo laboral é sem dúvida aquele em que os impactos desestruturadores da globalização têm se mostrado mais problemáticos", com impactos devastadores "para milhões de trabalhadores de diversos continentes". A Europa não estaria fora disso, já que aí ocorrem "as alterações em curso representam um flagrante retrocesso em face das conquistas alcançadas desde o século XIX".

Oquadro particular da sociedade portuguesa não seria dos melhores. Nesse sentido, "se o consumismo desenfreado e as expectativas de mobilidade ascendente puderam alimentar tais ilusões durante algum tempo, com a entrada no novo milênio e, sobretudo perante o reforço da competitividade global, a contenção de custos, as pressões para a flexibilização e privatização [...], deram início a uma profunda mudança na esfera do emprego, evidenciando assim, uma vez mais, o caráter persistente e estrutural das nossas debilidades".

Com isso, muitos problemas "supostamente resolvidos há décadas ressurgiram, tais como a 
pobreza, a falta de qualificação de trabalhadores e empresários, as elevadas taxas de evasão escolar, o crescimento brutal das desigualdades sociais, o aumento do desemprego e da pobreza, as desigualdades de gênero e uma rápida precarização do trabalho, que atingiu em especial os setores mais jovens (incluindo os mais escolarizados)". No entendimento de Estanque, a crise atual, "ao mesmo tempo em que ameaça desfazer um conjunto de laços sociais que até aqui garantiam a coesão mínima da sociedade, pode [...] galvanizar de novo as multidões que se sentem ressentidas e desprotegidas". Uma ausência, de certa forma sentida, tem sido aquela dos sindicatos. Mas, para o autor, "o fato de o sindicalismo apenas timidamente se envolver nesse tipo de iniciativas, até agora, não garante que elas continuem a ter uma expressão modesta”. Contudo, para tanto, no enfrentamento dos "atuais desafios (que a crise apenas veio acelerar), o sindicalismo de hoje terá de se reinventar ou se reestruturar profundamente", buscar redes transnacionais, a partir da ideia do que seria um "sindicalismo de movimento social global".

Finalmente, diríamos que, apesar de ainda germinal, o debate acerca da sociologia pública poderá prosperar muito no Brasil. Afinal de contas, é difícil imaginar um lugar no mundo onde uma proposta como a elaborada por Burawoy faça mais sentido. Quais as razões que nos levam a afirmar isso? Em linhas gerais, diríamos que dois são os motivos principais.

Por um lado, temos a estrutura social brasileira: afinal, não é nenhum segredo que o Brasil é um dos países mais desiguais do planeta e que, portanto, oferece uma gigantesca quantidade de material histórico para uma sociologia crítica, reflexiva e engajada com públicos extra-acadêmicos a debruçar-se. E, por outro, temos a presença de uma larga tradição do fazer sociológico igualmente crítico e militante, cujo exemplo mais conhecido é, sem dúvidas, o de Florestan Fernandes, que dialoga fortemente com a sociologia pública. Por tudo isso, temos certeza de que os artigos presentes nesse dossiê encontrarão uma bem-aventurada acolhida por parte do público leitor da revista Caderno CRH.

(Recebido para publicação em julho de 2009) (Aceito em agosto de 2009)

\section{REFERÊNCIAS}

BECK, Ulrich. How not to become a museum piece. The British Journal of Sociology, v. 56, n. 3, 2005.

BOYNS, David; FLETCHER, Jesse. Reflections on public sociology: public relations, disciplinary identity, and the strong program in professional sociology. The American Sociologist, v. 36, n. 3, p. 5-26, 2005.

BRINT, Steven. Guide for a perplexed: on Michael Burawoy's "public sociology". The American Sociologist, v. 36, n. 3, p. 46-65, 2005.

BURAWOY, Michael. For public sociology. American Sociological Review, v. 70, fev., p. 4-28, 2005.

DEFLEM, Mathieu. Public sociology, hot dogs, apple pie, and chevrolet". The Journal of Professional and Public Sociology, v. 1, n. 1, dez. 2005.

GOULDNER, Alvin. The sociologist as partisan: sociology and the welfare state. American Sociologist, n. 3, 1968.

GRAMSCI, Antonio. Cadernos do cárcere. São Paulo: Civilização Brasileira, 1999.

MCLAUGHLIN, Neil; KOWALCHUK, Lisa; TURCOTTE, Kerry. Why sociology does not to be saved. The American Sociologist, v. 36, n. 3-4, p. 133-151, 2005.

TURNER, Jonathan. Is public sociology such a good idea? The American Sociologist, v. 36, n. 3-4, p. 27-45, 2005.

Ruy Braga - Doutor em Ciências Sociais pela Unicamp. Professor do Departamento de Sociologia da USP é Diretor do Centro de Estudos dos Direitos da Cidadania (Cenedic - USP). Desenvolve pesquisas nas áreas de Sociologia do Trabalho e Teoria Sociológica. Sua mais recente publicação é o livro intitulado Infoproletários: degradação real do trabalho virtual (co-autoria com Ricardo Antunes. São Paulo: Boitempo, 2009 (no prelo).

Marco Aurélio Santana - Doutor em Sociologia pela Universidade Federal do Rio de Janeiro - UFRJ. Professor do Departamento de Sociologia e Coordenador do Programa de Pós-Graduação em Sociologia e Antropologia da UFRJ. Desenvolve pesquisas na área de Sociologia do Trabalho, com ênfase em trabalhadores, sindicatos e ações coletivas. Publicou, entre outros: Homens partidos: comunistas e sindicatos no Brasil (São Paulo, Boitempo, 2001) e Sociologia do trabalho no mundo contemporâneo (em co-autoria com José Ricardo Ramalho, $2^{\mathrm{a}}$ edição, Rio de Janeiro, Jorge Zahar ed., 2009). 